\title{
Ventilator-Associated Pneumonia in Neonatal Patients: An Update
}

\author{
María Cernada ${ }^{a, b}$ María Brugada ${ }^{a, b}$ Sergio Golombek ${ }^{c}$ Máximo Vento $^{a, b}$ \\ a Neonatal Research Unit, Health Research Institute La Fe, and ${ }^{b}$ Division of Neonatology, University and Polytechnic \\ Hospital La Fe, Valencia, Spain; ' Regional Neonatal Center, Maria Fareri Children's Hospital, Westchester Medical \\ Center, New York Medical College, Valhalla, N.Y., USA
}

\section{Key Words}

Newborn · Mechanical ventilation · Infections .

Pneumonia $\cdot$ Intubation

\begin{abstract}
Ventilator-associated pneumonia (VAP) is a serious complication related to mechanical ventilation in the neonatal period. However, lack of a specific definition and difficulties obtaining noncontaminated samples of the lower respiratory airway render microbiological diagnosis and etiological treatment extremely difficult. Thus far, only few studies have approached VAP using accepted Centers for Disease Control and Prevention criteria and reliable sampling techniques. In recent years, however, the blind-protected bronchoalveolar lavage technique with protected specimen brush and the development of validated biomarkers have attempted to overcome the diagnostic difficulties and assess the response to therapy. This updated review on neonatal VAP aims to stimulate neonatologists' interest in this subtle but serious complication of mechanical ventilation.
\end{abstract}

(c) 2013 S. Karger AG, Basel

\section{Introduction}

The survival rate of extremely preterm infants in the last decades has substantially improved $[1,2]$. Interventions that have helped to achieve this include: regionaliza- tion of perinatal care, generalization of antenatal steroids, and postnatal supplementation with exogenous surfactant. In addition, changes introduced in the NICU, including new modalities of mechanical ventilation (MV), more efficient antibiotics, enhanced nutrition, and noninvasive point-of-care ultrasound diagnosis, have altogether contributed to lowering mortality especially among extremely-low-birth-weight infants [3].

Advances in MV have enabled the provision of respiratory support to extremely preterm infants within the limits of viability. However, baro- and volutrauma derived from MV cause cytoarchitectural changes and abnormal remodeling of the lung structure contributing to the development of chronic pulmonary disease. Additional complications secondary to MV include air leaks, interstitial emphysema, subglottic stenosis, and ventilator-associated pneumonia (VAP) [4]. Conspicuously, the most effective strategy proven to minimize ventilator-associated lung injury consists of reducing the duration of MV [5]. However, in spite of these recommendations, the rates of endotracheal intubation reported by the National Nosocomial Infection Surveillance System (NNIS) from January 2002 to June 2004 were still 43\% in neonates with a birth weight of less than $1,000 \mathrm{~g}$ and $16 \%$ in newborns with a birth weight between 1,000 and $1,499 \mathrm{~g}[6]$.

This review aims to update the scientific literature related to neonatal VAP and thereby draw attention to this severe and frequent complication of MV.

\section{KARGER}

(C) 2013 S. Karger AG, Basel

1661-7800/13/1052-0098\$38.00/0

E-Mail karger@karger.com

www.karger.com/neo
Prof. Máximo Vento, $\mathrm{MD}, \mathrm{PhD}$

Neonatal Research Unit, Division of Neonatology

University and Polytechnic Hospital La Fe

Bulevar Sur s/n, ES-46026 Valencia (Spain)

E-Mail maximo.vento@uv.es 
Table 1. Diagnostic criteria for VAP in infants younger than 1 year

\begin{tabular}{|c|c|}
\hline Radiological signs & $\begin{array}{l}\text { Patient with one or more (in patients with underlying diseases two or more) chest X-rays with one of the } \\
\text { following findings: } \\
\text { - new or progressive and persistent infiltrate } \\
\text { - consolidation } \\
\text { - cavitation } \\
\text { - pneumatoceles }\end{array}$ \\
\hline $\begin{array}{l}\text { Clinical signs and } \\
\text { symptoms }\end{array}$ & $\begin{array}{l}\text { Worsening of gas exchange [e.g. oxygen desaturations }(\mathrm{e} . \mathrm{g} \text {. pulse oximetry }<94 \%) \text {, increased oxygen } \\
\text { requirements, or increased ventilation demand] and three of the following: } \\
\text { - temperature instability with no other recognized cause } \\
\text { - leukopenia }\left(<4,000 \mathrm{WBC} / \mathrm{mm}^{3}\right) \text { or leukocytosis }\left(>15,000 \mathrm{WBC} / \mathrm{mm}^{3}\right) \text { and left shift }(>10 \% \text { band forms }) \\
\text { - new onset of purulent sputum, or change in the character of sputum, or increase in respiratory secretions, } \\
\text { or increased suctioning requirements } \\
\text { - apnea, tachypnea, nasal flaring with retraction of chest wall or grunting } \\
\text { - wheezing, rales, or rhonchi } \\
\text { - cough } \\
\text { - bradycardia }(<100 \text { beats } / \mathrm{min}) \text { or tachycardia }(>170 \text { beats } / \mathrm{min})\end{array}$ \\
\hline
\end{tabular}

$\mathrm{WBC}=$ White blood cells; LRT $=$ lower respiratory tract CFU $=$ colony-forming units.

\section{Definition of VAP}

The Centers for Disease Control and Prevention (CDC; Atlanta, Ga., USA) defines VAP as 'a nosocomial infection diagnosed in patients undergoing $\mathrm{MV}$ for at least 48 h' [7]. It is noteworthy that diagnosis of a VAP episode requires a combination of radiological, clinical, and laboratory criteria (table 1) [7]. However, CDC/ NNIS criteria refer to infants younger than 1 year and do not define specific criteria for the newborn period in term or preterm infants. In spite of this lack of specificity, most studies of VAP performed in NICUs are based on these criteria [8].

Moreover, etiological diagnosis is hindered by the difficulty in obtaining noncontaminated samples from the infants' airways.

The CDC permits the diagnosis of 'clinically defined pneumonia', based only on clinical and radiological findings, without any isolated pathogen. Nevertheless, some authors have emphasized the importance of microbiolog- ical diagnosis in the adult population to avoid VAP overdiagnosing [9]. On the other hand, isolation of pathogens without clinical and radiological signs is not diagnostic of VAP and could just represent colonization of the airways. Hence, microbiological criteria for neonatal VAP diagnosis has been a prerequisite only in some studies [10-12], while in others only clinical and/or microbiological criteria have been required [13-15].

\section{Incidence}

According to data published by the NNIS program sponsored by the CDC, VAP is the second most frequent cause of nosocomial infection (20\% of nosocomial infections) in pediatric intensive care units (PICU), with rates that oscillate from 1.4 to 7 episodes per 1,000 ventilator days $[6,16,17]$. In developing countries the reported rates are significantly higher, ranging from 16.1 to 89 episodes per 1,000 ventilator days $[12,18,19]$. 
Table 2. Description of the most relevant features of studies published in relation to VAP in the neonatal period

\begin{tabular}{|c|c|c|c|c|c|c|c|}
\hline & Afjeh et al. [12] & $\begin{array}{l}\text { Apisarnthanarak et al. } \\
\text { [13] }\end{array}$ & $\begin{array}{l}\text { Cernada et al. } \\
{[10]}\end{array}$ & Deng et al. [18] & $\begin{array}{l}\text { Geffers et al. } \\
{[14]}\end{array}$ & Tripathi et al. [11] & $\begin{array}{l}\text { Yuan et al. } \\
\text { [15] }\end{array}$ \\
\hline Study design & $\begin{array}{l}\text { Prospective } \\
\text { cohort }\end{array}$ & Prospective cohort & $\begin{array}{l}\text { Prospective } \\
\text { cohort }\end{array}$ & $\begin{array}{l}\text { Retrospective } \\
\text { case-control }\end{array}$ & $\begin{array}{l}\text { Prospective } \\
\text { surveillance }\end{array}$ & $\begin{array}{l}\text { Prospective } \\
\text { cohort }\end{array}$ & $\begin{array}{l}\text { Retrospective } \\
\text { cohort }\end{array}$ \\
\hline Population & $\begin{array}{l}\text { Newborn; } \\
\text { MV > } 48 \text { h }\end{array}$ & $\begin{array}{l}\text { BW }<2,000 \mathrm{~g} \\
\mathrm{MV}>48 \mathrm{~h}\end{array}$ & $\begin{array}{l}\text { Newborn; } \\
\text { MV > } 48 \text { h }\end{array}$ & $\begin{array}{l}\text { Newborn; } \\
\text { MV > } 48 \text { h }\end{array}$ & $\begin{array}{l}\mathrm{BW}<1,500 \mathrm{~g} \\
\mathrm{MV}>48 \mathrm{~h}\end{array}$ & $\begin{array}{l}\text { Newborn; } \\
\text { MV > } 48 \text { h }\end{array}$ & $\begin{array}{l}\text { Newborn; } \\
\text { MV > } 48 \text { h }\end{array}$ \\
\hline Incidence $^{1}$ & 11.6 episodes & $\begin{array}{l}<28 \text { weeks: } 6.5 \text { episodes } \\
>28 \text { weeks: } 4 \text { episodes }\end{array}$ & 10.9 episodes & Prevalence: $33.5 \%$ & 2.7 episodes & 37.2 episodes & $\begin{array}{l}\text { Prevalence: } \\
20.1 \%\end{array}$ \\
\hline $\begin{array}{l}\text { Sampling } \\
\text { method }\end{array}$ & ET aspirate & ET aspirate & $\begin{array}{l}\text { Blind-protected } \\
\text { BAL }\end{array}$ & ET aspirate & Not provided & ET aspirate & ET aspirate \\
\hline Outcome & Not provided & $\begin{array}{l}\text { Increased mortality } \\
\text { Increased LOF }\end{array}$ & Increased LOF & Not provided & Not provided & $\begin{array}{l}\text { Increased mortality } \\
\text { Increased LOF }\end{array}$ & $\begin{array}{l}\text { Increased } \\
\text { LOF }\end{array}$ \\
\hline
\end{tabular}

${ }^{1}$ Expressed as episodes per 1,000 ventilator days. BW = Birth weight; ET = endotracheal; LOF = length of stay; CONS = coagulase-negative staphylococci.

Focusing exclusively on the neonatal population accounted for, the incidence is highly influenced by gestational age and regional economic development. Hence, while in developed countries the incidence oscillates between 2.7 to 10.9 episodes per 1,000 ventilator days, in developing countries it may reach up to 37.2 cases per 1,000 ventilator days $[6,10,11,13,14,20]$. This variability could also be explained by the use of different criteria to define VAP (table 2).

\section{Pathogenesis and Pathogens}

Microorganisms invading the respiratory airways and infecting the lung parenchyma may cause VAP. In his excellent review article, Garland [21] describes the possible sources of microorganisms and the pathogenic mechanisms by which they may cause VAP. Endogenous sources of microorganisms comprise colonization of the naso-/ oropharynx, gastric fluid pool, or tracheal secretions. Aspiration of these contaminated fluids into the lung can result in pneumonia. Contrarily, blood-borne seeding of the lung constitutes a rare cause of VAP. Moreover, pathogens can also reach the lung from exogenous sourc- es such as the hands of healthcare workers, ventilator circuits, and the biofilm of endotracheal tubes (ETT) [21].

The difficulty in obtaining noncontaminated samples renders the assessment of VAP etiology difficult. Apisarnthanarak et al. [13] reported isolation of multiple organisms from tracheal aspirates (TA) in 58\% of episodes of VAP in extremely preterm neonates. In addition, Deng et al. [18] (in neonates) and Srinvasan et al. [22] (in pediatric patients) informed of a polymicrobial etiology in 25 $40 \%$ of VAP episodes. Of note, in these studies, samples were retrieved from ETT instead of using invasive sampling techniques of the lower respiratory tract, and therefore they might represent colonization instead of true infection. Conspicuously, when focusing on studies that used invasive techniques for sample collection, polymicrobial etiology represented only $16.7 \%$ of the VAP episodes [10].

The most common pathogens isolated in the neonatal population are Pseudomonas aeruginosa and Staphylococcus aureus $[10,13,15]$. However, isolation of other microorganisms such as Klebsiella pneumoniae and Escherichia coli has also been reported $[11,12,23]$ (table 2).

There is evidence that Ureaplasma urealyticum-derived inflammation in different compartments (intrauterine, 
lung, blood, or brain) during a common developmental window of vulnerability contributes to preterm labor and lung and brain injury [24]. Although no mention of this agent has been made in the literature as a causative agent of VAP, it could be a confounding factor overlapping with VAP diagnosis. Therefore, Ureaplasma should be looked for in cultured samples and if present it should be take into consideration when prescribing antibiotic therapy.

\section{Sample Collection Methods}

The use of diagnostic techniques with high false-positive rates increases antibiotic prescription and results in selection pressure for multidrug-resistant bacteria and increased costs [25]. Currently, both noninvasive and invasive (bronchoscopic) techniques are equally employed for sample collection. Bronchoalveolar lavage (BAL) is highly specific but invasive and only effective in experienced hands. Contrarily, noninvasive techniques such as TA are more accessible and easy to use, but they tend to overdiagnose VAP and, as a result, increase the use of antibiotics [9].

Bronchoscopic BAL and protected specimen brush (PSB) have been increasingly adopted for sample collection in VAP-suspected adults. These techniques are highly reliable as they avoid sample contamination and constitute at present the standard for microbiological sampling in the respiratory airways [26]. Gauvin et al. [27] performed a prospective cohort study in PICU patients with suspicion of VAP and concluded that blind BAL with a bacterial index (sum of the log of all species obtained from BAL) $\geq 5$ was the most reliable method for diagnosing VAP. Labenne et al. [28] tested the sensitivity and specificity of BAL and PBS in children and neonates with suspected VAP. As reference standards they used positive pleural fluid, positive lung biopsy, histopathological evidence, pulmonary abscesses in computed tomography scans, isolation of identical bacteria in blood and TA cultures or clinical diagnosis using CDC guidelines evaluated by two independent investigators blinded for BAL/PSB. They reported $72 \%$ sensitivity and $88 \%$ specificity for BAL culture, which increased to 79 and $88 \%$, respectively, when combined with an intracellular bacteria count. A combination of these techniques with PSB reached a sensitivity of $90 \%$ and a specificity of $88 \%$. Furthermore, both techniques seemed to be safe and only minor complications such as minimal bronchial hemorrhage, a moderate increase in oxygen or ventilator requirement, and transient fever were reported [28].

VAP in Neonates
Unfortunately, bronchoscopic BAL and PSB are not applicable in neonatology because of the small diameter of the ETT. Under these circumstances, blind-protected BAL appears to be the most reliable sampling method in the neonatal patient [10]. Thus, in a recent prospective observational study including 198 neonates intubated for more than $48 \mathrm{~h}$ who fulfilled CDC criteria for VAP, lower airway secretions were collected using the BAL technique with a blind-protected catheter under sterile conditions. A total of 18 episodes of VAP were diagnosed. Among the causative agents there was a predominance of Gram-negative bacteria representing $61.9 \%$ of the total isolated bacteria, with $P$. aeruginosa being the most frequently isolated microorganism (19\%). Other relevant pathogens were coagulase-negative staphylococci and S. aureus, while $16.7 \%$ of the cultures were polymicrobial [10].

\section{Clinical Signs and Risk Factors}

According to CDC criteria, VAP diagnosis should only be considered after $48 \mathrm{~h}$ of MV.

However, it should be underscored that different studies have reported a wide range of days of MV before the VAP diagnosis was made. Hence, while some authors have reported VAP diagnoses in the range of 21-39 days after the initiation of MV [10,12, 13, 29], others have reported diagnoses as early as 4-10 days after the start of MV $[11,15,30]$.

The most prevalent clinical sign associated with VAP refers to changes in the characteristics and volume of respiratory secretions and the appearance of purulent mucus in TA. Other signs include hypo- or hyperthermia and worsening of the respiratory distress $[10,12,13,15]$.

There are a series of risk factors that predispose to VAP (table 3). Among them, perhaps prematurity and days of MV are the most relevant ones. Prematurity is characterized by an anatomic and functional immaturity of the lung and respiratory airways together with immature antioxidant defense and immune systems. These peculiarities prompt the need for respiratory support and the tendency towards inflammation and infection, all of which favor the appearance of VAP [3]. Very low birth weight (VLBW), described by Afjeh et al. [12] and Tripathi et al. [11] as an additional independent risk factor for developing VAP, should be considered a possible confounder since extremely-low-birth-weight infants need MV for prolonged periods of time compared to term infants [1]. 
Duration of ventilation has been acknowledged in studies performed with different sampling methods. Hence, Cernada et al. [10], Afjeh et al. [12], and Tripathi et al. [11] identified duration of MV as the most common risk factor. Of note, Cernada et al. [10] employed a novel invasive bronchoalveolar technique to avoid sample contamination for the first time in neonates.

\section{Diagnostic Biomarkers}

In 2001, a panel of the NIH put forth a broad definition of biomarker, describing it as a 'characteristic that is objectively measured and evaluated as an indicator of normal biological processes, pathogenic processes, or pharmacological responses to a therapeutic intervention' [29]. Specific biomarkers of VAP allowing differentiation of pneumonia from colonization have been extensively studied in the adult population, albeit with unreliable results probably due to inconsistencies in the design of most of the studies [30]. Therefore, studies targeting the role of biomarkers in predicting/diagnosing VAP should employ validated sampling techniques to obtain BAL fluid and secretions, disregard patients under antibiotic or corticosteroid therapy prior to sampling, apply similar sensitivity and specificity cutoff values as reported in the literature, and include a homogeneous patient population [31].

\section{Procalcitonin}

Procalcitonin (PCT) is a prohormone secreted into serum as part of the systemic inflammatory response to endotoxin or mediators released in response to bacterial infections [interleukin (IL)-1 $\beta$, IL-6, or TNF- $\alpha$ ]. Interestingly, upregulation of PCT is inhibited by interferon (IFN)- $\gamma$, a cytokine released in response to viral infections rendering PCT more suitable to identify bacterial infections [32]. The PCT kinetic profile is extremely favorable for use as a clinical marker. Hence, after only $6-12 \mathrm{~h}$ of stimulation PCT blood levels will increase and once the infection is controlled these values will descend rapidly [33]. PCT has been widely used for VAP diagnosis and follow-up in the adult population. However, the results provided by these studies have been very inconsistent, reporting great variability in the cutoff values and broad ranges of sensitivity and specificity [34-36], or even informing of a lack of association between PCT concentration and adequacy of therapy, etiology of VAP, or outcome [37].
Table 3. Risk factors for the development of VAP in the newborn period

\begin{tabular}{|c|c|c|}
\hline Risk factor & $\begin{array}{l}\text { Specific } \\
\text { reference }\end{array}$ & $\begin{array}{l}\text { General } \\
\text { reference }\end{array}$ \\
\hline Prematurity and/or low birth weight & $11,12,30$ & \\
\hline Reintubation & 15 & \\
\hline Primary blood stream infection & 13 & \\
\hline Prior antibiotic use & & $27,33,34,35$ \\
\hline Sedation & & $27,33,34,35$ \\
\hline Enteral feeds & & $27,33,34,35$ \\
\hline Parenteral nutrition & 19 & \\
\hline Endotracheal suctioning & 15 & \\
\hline Days of MV & $\begin{array}{l}10,11,12 \\
15,19\end{array}$ & \\
\hline Transfusion of any blood product & & $27,33,34,35$ \\
\hline Genetic syndrome & & $27,33,34,35$ \\
\hline Steroids & 19 & \\
\hline Histamine type 2 receptor blockers & & $27,33,34,35$ \\
\hline
\end{tabular}

\section{Cytokines}

The presence of bacterial pathogens will be sensed by specific cytosolic receptors such as Toll-like and Nod-like receptors triggering an inflammatory response. Proinflammatory cytokines such as IL-1, IL-6, IL-8, IL-10, and TNF- $\alpha$ have been evaluated in adults as markers of VAP, with discordant results. Conway Morris et al. [38] published an association between VAP and increased values of IL- $1 \beta$ and IL- 8 measured in BAL. Ramírez et al. [39] found that IL- 6 was capable of accurately differentiating VAP from other causes of pulmonary infiltrates and therefore early IL- 6 determination could be a reliable marker for patients at increased risk of VAP. Cytokines have also been rendered useful for monitoring the response to antibiotic treatment. Swanson et al. [40] reported that pulmonary concentrations of IL- 8 and TNF- $\alpha$ decreased in microbiological responders with VAP; however, the sample size was relatively small and the results should be confirmed.

\section{The Soluble Form of the Triggering Receptor}

Expressed on Myeloid Cells

The triggering receptor expressed on myeloid cells (TREM) is related to the natural killer cell receptors and is constitutively expressed on the surface of myeloid cells, neutrophils, monocytes, and macrophages. The expression of TREM-1 is upregulated after stimulation with bacterial and fungal products, and it is involved in mediating proinflammatory responses. The triggering soluble form of TREM (s-TREM) reflects an activation of phago- 
cytes and has been proposed as a biomarker of VAP. Determann et al. [41] measured s-TREM in adult patients with VAP and controls and did not find differences in plasma levels; however, levels in BAL were higher in patients with VAP. These results differed from those published by Horoneko et al. [42], who did not find differences in s-TREM concentrations between patients with VAP and controls. Srinivasan et al. [43] evaluated the role of s-TREM and plasminogen activation inhibitor-1 (PLA1 ) in the diagnosis of VAP in a PICU. They reported that elevated levels of PLA-1 had the strongest association with a clinical diagnosis of VAP and were the best biomarker to differentiate VAP from colonization.

\section{Oxidative Stress}

Following neutrophil activation through TREM-1, a burst of reactive oxygen species including hypochlorous acid $(\mathrm{HOCl})$, the only source of which is the neutrophil enzyme myeloperoxidase, is generated. $\mathrm{HOCl}$ is too short-lived and cannot, therefore, be measured in biological materials. However, the effects of $\mathrm{HOCl}$ on other molecules such as tyrosine can be measured by mass spectrometry in biofluids in the form of 3-chloro-tyrosine [44]. Another relevant candidate reflecting the prooxidant action of $\mathrm{HOCl}$ is glutathione sulfonamide (GSA), a stable oxidation product of reduced glutathione (GSH). GSH is extremely abundant in the cells' cytoplasm but especially in the lung lining fluid. Therefore, GSA can be easily determined in BAL fluid. As infectious agents promote sequestration and activation of neutrophils at the inflammatory site, VAP should cause an increase in this specific biomarker in lung lavage fluid [45].

Few studies (and with disappointing results) on the use of biomarkers in neonatology have been reported. Hence, PCT has been extensively employed for the diagnosis of suspected sepsis and for guiding the duration of antibiotic treatment [46]. However, the presence of a normal, physiological surge in serum PCT $24 \mathrm{~h}$ after birth lasting up to $72 \mathrm{~h}$ has precluded its use in the early neonatal period, especially for the diagnosis of early-onset sepsis [47]. Of note, no study has yet established an association of PCT with neonatal VAP. Similarly, although cytokines and especially IL- 6 have been successfully employed in the diagnosis of early-onset neonatal sepsis [48], no study correlating plasma interleukin levels and VAP has been published. Harwood et al. [49] detected GSA in 75\% of TA of ventilated preterm infants. GSA median levels were significantly higher in culture-positive aspirates. In addition, GSA showed good sensitivity and specificity for detecting bacterial growth and has promise for detecting lung infection. Further studies should confirm the validity of this new biomarker. Finally, Gram staining studies on TA have also shown promising results. Katayama et al. [23] recently reported a sensitivity of 82 and $100 \%$, and a specificity of 100 and $82 \%$ for Gram-positive and Gramnegative VAP, respectively, in VLBW infants. Furthermore, Gram-stained TA-based initial antibiotic therapy was effective in $96 \%$ of the cases. These results should, however, be carefully interpreted for they did not fulfill CDC VAP diagnostic criteria [7].

\section{Outcomes}

In a large European multicenter trial it was shown that nosocomial infections were associated with increased PICU/NICU and total hospital length of stay. In addition, the mortality of infected patients was also significantly increased. However, VAP patients' mortality was no different from that of patients with infections in other locations [50]. Other studies have confirmed that VAP is associated with increased morbidity, a longer duration of $\mathrm{MV}$, and a longer hospital and/or ICU length of stay [17, 27, 51, 52]. Fischer et al. [53] reported an incidence of VAP of $9.6 \%$ in a neonatal and pediatric population after cardiac surgery and found a delay in extubation of 3.7 days attributable to VAP. Similarly, Srinivasan et al. [22], Elward et al. [54], and Gautam et al. [17] reported an increased length of stay and a longer duration of ventilation in pediatric and neonatal VAP patients with a tendency towards increased mortality that did not reach statistical significance $[27,51,52]$.

Focusing on studies conducted exclusively in neonatal populations, Apistharnarak et al. [13] found VAP to be an independent predictor of mortality in VLBW infants; moreover, VAP significantly increased the NICU length of stay. Tripathi et al. [11], Yuan et al. [15], and Cernada et al. [10] reported significantly higher NICU and hospital lengths of stay in NICU patients, respectively. Although they reported higher mortality rates in VAP patients, the differences did not reach statistical significance (table 2).

Increased length of stay and morbidity causes VAP to increase hospital costs. In a 2-year study performed in PICU patients, VAP was independently associated with increased costs, after controlling for other predictors of cost including age, underlying disease, ventilator days, and severity of illness [55]. In addition, after implementation of the VAP prevention bundle, Brilli et al. [56] reported a decrease in VAP rates and therefore a significant reduction in hospital costs. 


\section{Treatment}

Understanding the microbiology of VAP is critical for choosing empirical broad-spectrum antibiotic therapy followed by de-escalation to specific antimicrobial therapy once cultures are known or discontinuation of antibiotics if VAP is no longer suspected. However, there are no consensus guidelines for antibiotic treatment either in neonates or in children, and empirical treatment should be selected according to the nosocomial flora and resistance patterns of each individual unit. Interestingly, in extensive drug-resistant infections, aerosolized administration may be an appropriate route to deliver antibiotics and reduce systemic toxicity. Hence, Nakwan et al. [57] reported successful treatment of VAP due to Acinetobacter baumanii in a small series of preterm and term neonates with aerosolized colistin for $72 \mathrm{~h}$ associated with standard intravenous antibiotic therapy. No relevant side effects were noted and mortality was lower than in historical controls treated exclusively with intravenous antibiotics. Although these are promising data, more studies are needed to expand aerosolized antibiotic therapy in the newborn period, especially in drug-resistant pathogens.

The duration of antibiotic administration for VAP in the newborn period is still unknown. No published data in this regard are available in the literature. Therefore, until reliable information is accessible, the use of biomarkers of infection such as $\mathrm{C}$-reactive protein or interleukins combined with the clinical course and radiological findings are the mainstay for deciding the duration of antibiotic therapy.

\section{Prevention}

Most studies of VAP in neonates focus on clinical signs, pathogens, risk factors, and outcomes. Surveillance strategies and evaluation of their effectiveness oriented toward preventing VAP in the neonatal period are scarce but of growing interest. No conclusive results have been reported on how to prevent VAP in the neonatal period; however, implementation of hygienic measures and early extubation are apparently the most efficient strategies to reduce VAP [58, 59].

\section{ETT and Suction}

To date, no specific recommendations related to types of ETT or airway suction have been addressed for newborn infants. However, for adults and pediatric patients the CDC and Healthcare Infection Control Practices Ad- visory Committee suggest the use of ETT with dorsal lumens to allow drainage of respiratory secretions, orotracheal instead of nasotracheal intubation, and a change of ventilators' respiratory circuits only if they are visibly contaminated or do not work [60]. Interestingly, uncuffed ETT, commonly used in neonatal patients, could be a risk factor for increasing the incidence of VAP. Hence, in adults the use of polyurethane or taper-shaped cuffed ETT correlated with lower rates of VAP [51]. Intriguingly, the use of cuffed ETT in the pediatric population was associated with a reduced need for ETT changes and postextubation stridor but increased days of MV [61].

The use of ETT with nano-modified coatings apparently reduces the incidence of infections in the respiratory airways. Recently, Machado et al. [62], in a study performed in adults, reported that ETT with nano-modified coatings reduced the incidence of VAP by preventing biofilm formation and ETT colonization and providing free radical destruction of pathogens. Of note, published experiences in the neonatal period are lacking.

In relation to airway suctioning, Cordero et al. [63] compared the use of closed versus open endotracheal suction systems in ventilated neonates. No differences in the incidence of VAP or mortality between groups were found. Most nurses, however, found closed suction systems easier and faster to use and better tolerated by patients.

\section{Hand Washing}

Routine hand washing is one of the most important strategies to reduce nosocomial infections [64]. In a 2 -year-long surveillance intervention with NICU patients, increased hand hygiene compliance (from 43 to $80 \%$ ) significantly reduced the incidence of respiratory infections from 3.35 to 1.06 infections per 1,000 patient days [65]. In another study, systematic use of alcoholbased gels for hand hygiene by caregivers reduced the rate of VAP in VLBW infants by $38 \%$ [66].

\section{Rapid Extubation}

Since the duration of MV appears to be a major risk factor for the development of VAP in neonates, promptly weaning patients off the ventilator appears to be a desirable strategy to prevent VAP. Ng et al. [67], in a prospective study targeting reduction of the nosocomial infection rate in the NICU, implemented more aggressive strategies for the early weaning of patients off the ventilator during 3 months. When 1 year preintervention and 1 year postintervention were compared, the VAP rates decreased from 3.3/1,000 ventilator days to $1.0 / 1,000$ ventilator days [67]. 


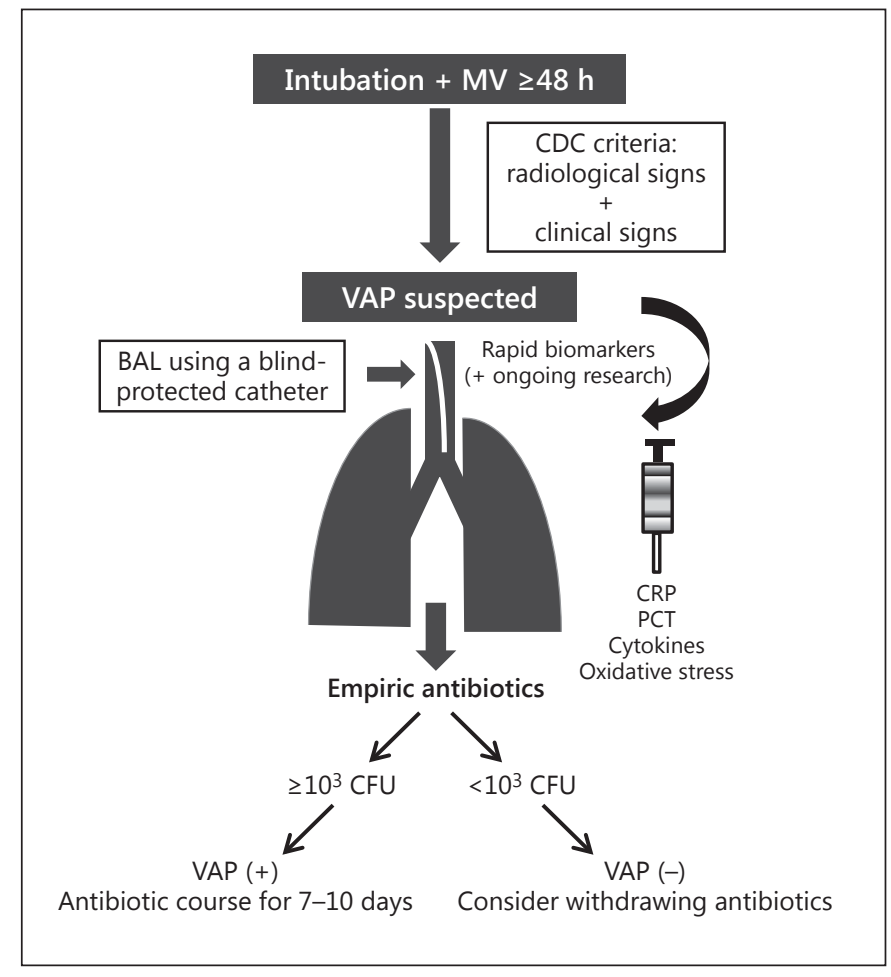

Fig. 1. Diagnostic algorithm for neonatal VAP in newborns. CRP = $\mathrm{C}$-reactive protein; $\mathrm{CFU}=$ colony-forming units.

Use of Histamine 2 Receptor Antagonists or Antacids

The use of histamine 2 receptor antagonists or antacids is believed to increase the risk of VAP as acid gastric content may make colonization with pathogenic organisms difficult. However, no differences in the incidence of VAP were found when comparing patients using or not using histamine 2 receptor antagonists or antacids [68]. There is no published experience in the neonatal period.

\section{Selective Decontamination}

Selective decontamination consists of the establishment of a regimen of topical or intravenous antimicrobials in an attempt to reduce the burden of pathogenic bacteria in aspirated secretions. Randomized studies in pediatric patients have shown conflicting results $[69,70]$. In a prospective cohort nonrandomized study, NICU patients received oral polymixin $\mathrm{E}$, tobramycin, and nystatin correctly (during the first 5 days) or incorrectly (after 5 days) or they did not receive any decolonization [71]. Results revealed that correct selective decolonization had a protective effect toward nosocomial infections of an intestinal origin. However, a separate analysis of the impact on respiratory infections alone was not performed [71]. Ac- cordingly, no recommendation regarding selective decontamination in neonates is warranted.

\section{Probiotics}

The loss of gut commensals such as Bifidobacterium and Lactobacilli spp. is associated with prolonged antibiotic treatments, delayed enteral feeding, or nursing in incubators and translates into proliferation of pathogenic microflora and abnormal gut colonization. Seemingly, enhancement of the enteric microbiota composition with supplementation of probiotics seems to be a good strategy to prevent sepsis and could also be applied to prevent neonatal VAP [72]. Nevertheless, a recent meta-analysis of 7 randomized controlled trials conducted in adult populations concluded that probiotics showed no beneficial effect in patients who are mechanically ventilated, did not significantly decrease the incidence of VAP, and should not be recommended for routine clinical application [73]. To date, no information regarding the use of probiotics to prevent VAP is available.

\section{Conclusions}

VAP remains a serious and mainly unsolved problem among pediatric and neonatal intensive care units [59]. VAP increases respiratory morbidity and overall mortality and prolongs the hospital length of stay. VAP is especially associated with prematurity, low birth weight, chronic lung disease, and prolonged MV [58]. However, clinical and radiological diagnosis is extremely difficult given the unspecific signs and symptoms of VAP in the neonatal patient. In addition, retrieving noncontaminated biological samples from the lower respiratory airways for culture is still a major challenge. The use of BAL with blind-protected catheters seems to be a valid alternative. However, there is an urgent need for trials comparing BAL with traditional TA for culture as well as identifying reliable biomarkers of lung infection as the best way to diagnose VAP and improve the outcomes in ventilated neonates.

We propose a diagnostic approach to VAP in the flow diagram depicted in figure 1. It is important that caregivers treating ventilated preterm infants keep this diagnosis in mind when a sudden worsening of a patient with risk factors occurs and clinical signs suggest this entity. As a general rule, patients should be extubated as soon as possible as a main strategy to prevent VAP. This update aims to draw attention to this subtle but severe complication affecting preterm infants in the NICU. 


\section{References}

1 Fanaroff AA, Stoll BJ, Wright LL, et al: Trends in neonatal morbidity and mortality for very low birthweight infants. Am J Obstet Gynecol 2007;196:147.e141-e148.

$>2$ Markestad T, Kaaresen PI, Ronnestad A, et al: Early death, morbidity, and need of treatment among extremely premature infants. Pediatrics 2005;115:1289-1298.

$>3$ Vento M, Cheung PY, Aguar M: The first golden minutes of the extremely-low-gestational-age neonate: a gentle approach. Neonatology 2009;95:286-298.

$>4$ Miller JD, Carlo WA: Pulmonary complications of mechanical ventilation in neonates. Clin Perinatol 2008;35:273-281, x-xi.

$\checkmark 5$ Ambalavanan N, Carlo WA: Ventilatory strategies in the prevention and management of bronchopulmonary dysplasia. Semin Perinatol 2006;30:192-199.

-6 National Nosocomial Infections Surveillance System: National Nosocomial Infections Surveillance (NNIS) System Report, data summary from January 1992 through June 2004, issued October 2004. Am J Infect Control 2004;32:470-485.

7 Centers for Disease Control and Prevention: Criteria for defining nosocomial pneumonia. www.cdc.gov/ncidod/hip/NNIS/members/ penumonia/Final/PneuCriteriaFinal.pdf (accessed January 17, 2009).

$>8$ Baltimore RS: The difficulty of diagnosing ventilator-associated pneumonia. Pediatrics 2003;112:1420-1421.

$>9$ Morris AC, Kefala K, Simpson AJ, et al: Evaluation of the effect of diagnostic methodology on the reported incidence of ventilator-associated pneumonia. Thorax 2009;64:516-522.

10 Cernada M, Aguar M, Brugada M, et al: Ventilator-associated pneumonia in newborn infants diagnosed with an invasive bronchoalveolar lavage technique: a prospective observational study. Pediatr Crit Care Med 2013; 14:55-61.

11 Tripathi SH, Malik GK, Jain A, Kohli N: Study of ventilator associated pneumonia in neonatal intensive care unit: characteristics, risk factors and outcome. Internet J Med Update 2010;5:12-19.

-12 Afjeh SA, Sabzehei MK, Karimi A, Shiva F, Shamshiri AR: Surveillance of ventilator-associated pneumonia in a neonatal intensive care unit: characteristics, risk factors, and outcome. Arch Iran Med 2012;15:567-571.

-13 Apisarnthanarak A, Holzmann-Pazgal G, Hamvas A, Olsen MA, Fraser VJ: Ventilatorassociated pneumonia in extremely preterm neonates in a neonatal intensive care unit: characteristics, risk factors, and outcomes. Pediatrics 2003;112:1283-1289.

$\checkmark 14$ Geffers C, Baerwolff S, Schwab F, Gastmeier $P$ : Incidence of healthcare-associated infections in high-risk neonates: results from the German surveillance system for very-lowbirthweight infants. J Hosp Infect 2008;68: 214-221.
15 Yuan TM, Chen LH, Yu HM: Risk factors and outcomes for ventilator-associated pneumonia in neonatal intensive care unit patients. J Perinat Med 2007;35:334-338.

16 Richards MJ, Edwards JR, Culver DH, Gaynes RP: Nosocomial infections in pediatric intensive care units in the United States - National Nosocomial Infections Surveillance System. Pediatrics 1999;103:e39.

17 Gautam A, Ganu SS, Tegg OJ, et al: Ventilator-associated pneumonia in a tertiary paediatric intensive care unit: a 1-year prospective observational study. Crit Care Resusc 2012; 14:283-289.

18 Deng C, Li X, Zou Y, et al: Risk factors and pathogen profile of ventilator-associated pneumonia in a neonatal intensive care unit in China. Pediatr Int 2011;53:332-337.

$>19$ Tullu MS, Deshmukh CT, Baveja SM: Bacterial nosocomial pneumonia in paediatric intensive care unit. J Postgrad Med 2000;46: 18-22.

20 Stover BH, Shulman ST, Bratcher DF, et al: Nosocomial infection rates in US children's hospitals' neonatal and pediatric intensive care units. Am J Infect Control 2001;29:152157.

21 Garland JS: Strategies to prevent ventilatorassociated pneumonia in neonates. Clin Perinatol 2010;37:629-643.

22 Srinivasan R, Asselin J, Gildengorin G, Wiener-Kronish J, Flori HR: A prospective study of ventilator-associated pneumonia in children. Pediatrics 2009;123:1108-1115.

23 Katayama Y, Minami H, Enomoto M, et al: Usefulness of Gram staining of tracheal aspirates in initial therapy for ventilator-associated pneumonia in extremely preterm neonates. J Perinatol 2010;30:270-274.

24 Thomas W, Speer CP: Nonventilatory strategies for prevention and treatment of bronchopulmonary dysplasia - what is the evidence? Neonatology 2008;94:150-159.

25 Dancer SJ, Coyne M, Robertson C, et al: Antibiotic use is associated with resistance of environmental organisms in a teaching hospital. J Hosp Infect 2006;62:200-206.

26 Sachdev A, Chugh K, Sethi M, et al: Diagnosis of ventilator-associated pneumonia in children in resource-limited setting: a comparative study of bronchoscopic and nonbronchoscopic methods. Pediatr Crit Care Med 2010; 11:258-266.

27 Gauvin F, Lacroix J, Guertin MC, et al: Reproducibility of blind protected bronchoalveolar lavage in mechanically ventilated children. Am J Respir Crit Care Med 2002;165:1618-1623.

28 Labenne M, Poyart C, Rambaud C, et al: Blind protected specimen brush and bronchoalveolar lavage in ventilated children. Crit Care Med 1999;27:2537-2543

29 Biomarkers Definitions Working Group: Biomarkers and surrogate endpoints: preferred definitions and conceptual framework. Clin Pharmacol Ther 2001;69:89-95.
30 el-Ebiary M, Soler N, Monton C, Torres A: Markers of ventilator-associated pneumonia. Clin Intensive Care 1995;6:121-126.

-31 Palazzo SJ, Simpson T, Schnapp L: Biomarkers for ventilator-associated pneumonia: review of the literature. Heart Lung 2011;40: 293-298.

32 Gilbert DN: Procalcitonin as a biomarker in respiratory tract infection. Clin Infect Dis 2011;52(suppl 4):S346-S350.

33 Schuetz P, Albrich W, Mueller B: Procalcitonin for diagnosis of infection and guide to antibiotic decisions: past, present and future. BMC Med 2011;9:107.

34 Luyt CE, Combes A, Reynaud C, et al: Usefulness of procalcitonin for the diagnosis of ventilator-associated pneumonia. Intensive Care Med 2008;34:1434-1440.

35 Oppert M, Reinicke A, Muller C, et al: Elevations in procalcitonin but not C-reactive protein are associated with pneumonia after cardiopulmonary resuscitation. Resuscitation 2002;53:167-170.

36 Duflo F, Debon R, Monneret G, et al: Alveolar and serum procalcitonin: diagnostic and prognostic value in ventilator-associated pneumonia. Anesthesiology 2002;96:74-79.

37 Zielinska-Borkowska U, Skirecki T, Zlotorowicz M, Czarnocka B: Procalcitonin in early onset ventilator-associated pneumonia. J Hosp Infect 2012;81:92-97.

38 Conway Morris A, Kefala K, Wilkinson TS, et al: Diagnostic importance of pulmonary interleukin-1beta and interleukin- 8 in ventilator-associated pneumonia. Thorax 2010;65: 201-207.

39 Ramírez P, Ferrer M, Gimeno R, et al: Systemic inflammatory response and increased risk for ventilator-associated pneumonia: a preliminary study. Crit Care Med 2009;37: 1691-1695.

-40 Swanson JM, Mueller EW, Croce MA, et al: Changes in pulmonary cytokines during antibiotic therapy for ventilator-associated pneumonia. Surg Infect (Larchmt) 2010;11:161167.

41 Determann RM, Millo JL, Gibot S, et al: Serial changes in soluble triggering receptor expressed on myeloid cells in the lung during development of ventilator-associated pneumonia. Intensive Care Med 2005;31:14951500.

42 Horonenko G, Hoyt JC, Robbins RA, et al: Soluble triggering receptor expressed on myeloid cell-1 is increased in patients with ventilator-associated pneumonia: a preliminary report. Chest 2007;132:58-63.

43 Srinivasan R, Song Y, Wiener-Kronish J, Flori HR: Plasminogen activation inhibitor concentrations in bronchoalveolar lavage fluid distinguishes ventilator-associated pneumonia from colonization in mechanically ventilated pediatric patients. Pediatr Crit Care Med 2011;12:21-27. 
44 Escobar J, Teramo K, Stefanovic V, et al: Amniotic fluid oxidative and nitrosative stress biomarkers correlate with fetal chronic hypoxia in diabetic pregnancies. Neonatology 2013;103:193-198.

-45 Harwood DT, Nimmo SL, Kettle AJ, Winterbourn CC, Ashby MT: Molecular structure and dynamic properties of a sulfonamide derivative of glutathione that is produced under conditions of oxidative stress by hypochlorous acid. Chem Res Toxicol 2008;21:1011 1016.

46 Stocker M, Fontana M, El Helou S, Wegscheider K, Berger TM: Use of procalcitoninguided decision-making to shorten antibiotic therapy in suspected neonatal early-onset sepsis: prospective randomized intervention trial. Neonatology 2010;97:165-174.

47 Assumma M, Signore F, Pacifico L, et al: Serum procalcitonin concentrations in term delivering mothers and their healthy offspring: a longitudinal study. Clin Chem 2000;46: 1583-1587.

-48 Cernada M, Badia N, Modesto V, et al: Cord blood interleukin- 6 as a predictor of early-onset neonatal sepsis. Acta Paediatr 2012; 101:e203-e207.

49 Harwood DT, Darlow BA, Cheah FC, et al: Biomarkers of neutrophil-mediated glutathione and protein oxidation in tracheal aspirates from preterm infants: association with bacterial infection. Pediatr Res 2011;69:28-33.

50 Raymond J, Aujard Y: Nosocomial infections in pediatric patients: a European, multicenter prospective study - European Study Group. Infect Control Hosp Epidemiol 2000;21:260263.

51 Blot S, Rello J, Vogelaers D: What is new in the prevention of ventilator-associated pneumonia? Curr Opin Pulm Med 2011;17:155159.

52 Vanlaere I, Libert C: Matrix metalloproteinases as drug targets in infections caused by gram-negative bacteria and in septic shock. Clin Microbiol Rev 2009;22:224-239, table of contents.

53 Fischer JE, Allen P, Fanconi S: Delay of extubation in neonates and children after cardiac surgery: impact of ventilator-associated pneumonia. Intensive Care Med 2000;26: 942-949.
54 Elward AM, Warren DK, Fraser VJ: Ventilator-associated pneumonia in pediatric intensive care unit patients: risk factors and outcomes. Pediatrics 2002;109:758-764.

55 Foglia E, Hollenbeak C, Fraser V, Elward A: Costs associated with nosocomial bloodstream infections and ventilator-associated pneumonia in pediatric intensive care unit patients (abstract 109). 16th Annu Meet Soc Healthcare Epidemiol, Chicago, 2006.

56 Brilli RJ, Sparling KW, Lake MR, et al: The business case for preventing ventilator-associated pneumonia in pediatric intensive care unit patients. Jt Comm J Qual Patient Saf 2008;34:629-638.

57 Nakwan N, Wannaro J, Thongmak T, et al: Safety in treatment of ventilator-associated pneumonia due to extensive drug-resistant Acinetobacter baumannii with aerosolized colistin in neonates: a preliminary report. Pediatr Pulmonol 2011;46:60-66.

58 Badr MA, Ali YF, Albanna EA, Beshir MR, Amr GE: Ventilator associated pneumonia in critically-ill neonates admitted to neonatal in tensive care unit, Zagazig University Hospitals. Iran J Pediatr 2011;21:418-424.

59 Foglia E, Meier MD, Elward A: Ventilatorassociated pneumonia in neonatal and pediatric intensive care unit patients. Clin Microbiol Rev 2007;20:409-425, table of contents.

-60 Tablan OC, Anderson LJ, Besser R, Bridges C, Hajjeh R: Guidelines for preventing healthcare-associated pneumonia, 2003: recommendations of CDC and the Healthcare Infection Control Practices Advisory Committee. MMWR Recomm Rep 2004;53:1-36.

61 Weiss M, Dullenkopf A, Fischer JE, Keller C, Gerber AC: Prospective randomized controlled multi-centre trial of cuffed or uncuffed endotracheal tubes in small children. Br J Anaesth 2009;103:867-873.

62 Machado MC, Cheng D, Tarquinio KM, Webster TJ: Nanotechnology: pediatric applications. Pediatr Res 2010;67:500-504.

63 Cordero L, Sananes M, Ayers LW: Comparison of a closed (Trach Care MAC) with an open endotracheal suction system in small premature infants. J Perinatol 2000;20:151156.
64 Pittet D, Dharan S, Touveneau S, Sauvan V, Perneger TV: Bacterial contamination of the hands of hospital staff during routine patient care. Arch Intern Med 1999;159:821-826.

65 Won SP, Chou HC, Hsieh WS, et al: Handwashing program for the prevention of nosocomial infections in a neonatal intensive care unit. Infect Control Hosp Epidemiol 2004;25: 742-746.

66 Rogers E, Alderdice F, McCall E, Jenkins J, Craig S: Reducing nosocomial infections in neonatal intensive care. J Matern Fetal Neonatal Med 2010;23:1039-1046.

67 Ng SP, Gomez JM, Lim SH, Ho NK: Reduction of nosocomial infection in a neonatal intensive care unit (NICU). Singapore Med J 1998;39:319-323.

68 Yildizdas D, Yapicioglu H, Yilmaz HL: Occurrence of ventilator-associated pneumonia in mechanically ventilated pediatric intensive care patients during stress ulcer prophylaxis with sucralfate, ranitidine, and omeprazole. J Crit Care 2002;17:240-245.

-69 Ruza F, Alvarado F, Herruzo R, et al: Prevention of nosocomial infection in a pediatric intensive care unit (PICU) through the use of selective digestive decontamination. Eur J Epidemiol 1998;14:719-727.

70 Barret JP, Jeschke MG, Herndon DN: Selective decontamination of the digestive tract in severely burned pediatric patients. Burns 2001;27:439-445.

71 Herruzo-Cabrera R, Garcia Gonzalez JI, Garcia-Magan P, del Rey-Calero J: Nosocomial infection in a neonatal intensive care unit and its prevention with selective intestinal decolonization: a multivariant evaluation of infection reduction. Eur J Epidemiol 1994;10:573580.

72 Manzoni P, De Luca D, Stronati M, et al: Prevention of nosocomial infections in neonatal intensive care units. Am J Perinatol 2013;30: 81-88.

73 Gu WJ, Wei CY, Yin RX: Lack of efficacy of probiotics in preventing ventilator-associated pneumonia probiotics for ventilator-associated pneumonia: a systematic review and metaanalysis of randomized controlled trials. Chest 2012;142:859-868. 